ARTICLE

https://doi.org/10.1038/s41467-021-24.032-9

\title{
Ni-catalyzed hydroaminoalkylation of alkynes with amines
}

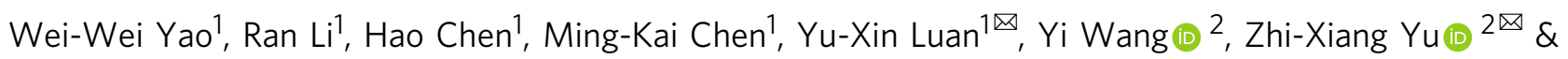
Mengchun $\mathrm{Ye}$ (10) ${ }^{1 \times}$

Allylic amines are versatile building blocks in organic synthesis and exist in bioactive compounds, but their synthesis via hydroaminoalkylation of alkynes with amines has been a formidable challenge. Here, we report a late transition metal Ni-catalyzed hydroaminoalkylation of alkynes with $\mathrm{N}$-sulfonyl amines, providing a series of allylic amines in up to $94 \%$ yield. Double ligands of $\mathrm{N}$-heterocyclic carbene $(\mathrm{IPr})$ and tricyclohexylphosphine $\left(\mathrm{PCy}_{3}\right)$ effectively promote the reaction.

\footnotetext{
${ }^{1}$ State Key Laboratory and Institute of Elemento-Organic Chemistry, College of Chemistry, Nankai University, Tianjin, China. ${ }^{2}$ Beijing National Laboratory for Molecular Sciences (BNLMS), Key Laboratory of Bioorganic Chemistry and Molecular Engineering of Ministry of Education, College of Chemistry, Peking

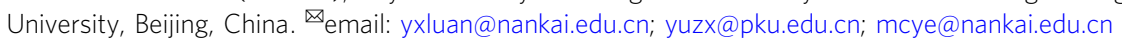


A llylic amines not only widely exist in a broad range of natural products and bioactive compounds, but also serve as versatile building blocks in organic synthesis ${ }^{1-4}$. The development of efficient and general methods for their synthesis has received much attention during the past several decades ${ }^{5-23}$. Among various reported methods, transition metal-catalyzed hydroaminoalkylation of $\pi$-unsaturated compounds, such as alkenes and alkynes represents one of the most straightforward and atom-economical synthetic routes ${ }^{24-31}$. With using either early $^{24-26}$ or late transition metals as catalysts ${ }^{27-31}$, a large number of hydroaminoalkylations of alkenes have been developed. However, in sharp contrast, analogous reactions of alkynes were faced with tremendous challenges (Fig. 1a), likely owing to difficult alkyne insertion and challenging protonolysis ${ }^{32-39}$. A pioneering investigation was conducted in 1989 by Buchwald and co-workers, who successfully obtained the allylic amine product by aqueous work-up. Despite an efficient protonolysis, the regeneration of $\mathrm{Zr}$ catalyst cannot be realized in this protocol, leading to stoichiometric $\mathrm{Zr}$-complex needed ${ }^{32}$. Since then, much effort has been devoted to improving the reaction ${ }^{33-39}$, while the development of a catalytic method has been an elusive challenge. Most recently, during our submission, Schafer group used a tetradentate bis(ureate) ligand and metal $\mathrm{Zr}$ to in situ form a bulky $\mathrm{Zr}$ catalyst, achieving a catalytic hydroaminoalkylation of alkynes for the first time (Fig. 1b) ${ }^{40,41}$. The bulky ligand proved critical to the reactivity, not only facilitating alkyne insertion, but also allowing the coordination of neutral amines to the metal center for subsequent easier protonolysis. Despite this big advance, the early transition metal $\mathrm{Zr}$-catalyzed method still suffered from some undesired limitations such as unavoidable hydroamination side reaction in many cases, difficult-to-remove $\mathrm{N}$-aryl protecting groups, and tricky regioselectivity under relatively harsh conditions. Therefore, the development of other efficient catalytic systems for hydroaminoalkylation of alkynes is still highly desirable. In this work, we use an inexpensive nickel as a catalyst to achieve a late transition metal-catalyzed hydroaminoalkylation of alkynes with $\mathrm{N}$-sulfonyl amines, providing a series of allylic amines in up to $94 \%$ yield (Fig. 1c). The reaction features relatively mild conditions $\left(80^{\circ} \mathrm{C}\right)$, general substrate scope of both amines and alkynes and high regioselectivity.

\section{Results}

Reaction optimization. In comparison with various hydroaminoalkylations of alkenes, the difficulty of hydroaminoalkylation of alkynes was ascribed to the following possible reasons: (1) strong basic and nucleophilic alkyl or aryl amines could coordinate to metal centers, resulting in either deactivation of transition metals or undesired side reactions such as hydroaminations; (2) weak acidity of $\mathrm{N}-\mathrm{H}$ bonds cannot effectively undergo protonolysis of metallocycle intermediates. Thereby, the selection of proper $\mathrm{N}$-protecting groups to increase the acidity of amines could be critical to the reaction efficiency, because more acidic amine would significantly reduce its coordination with metal centers and other side reactions such as hydroamination. However, to accommodate acidic $\mathrm{N}-\mathrm{H}$ bonds, sensitive early transition metal complexes should be replaced by late transition metals such as $\mathrm{Pd}, \mathrm{Ru}$ and $\mathrm{Ni}$, because they could have better compatibility with protic substrates and solvents.

Following this hypothesis, we conducted an extensive survey on N-protecting groups, transition metals, ligands and other reaction parameters. Ultimately, triisopropylbenzenesulfonyl

a

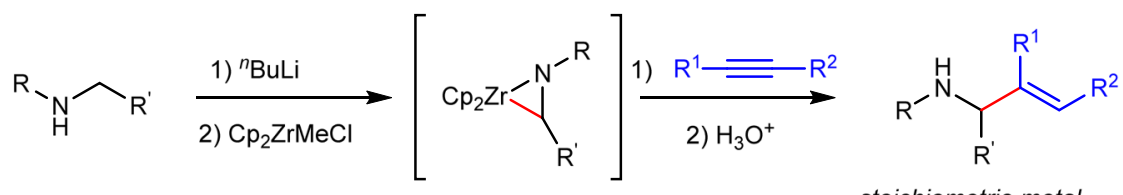

Elusive challenge: catalytic method

b

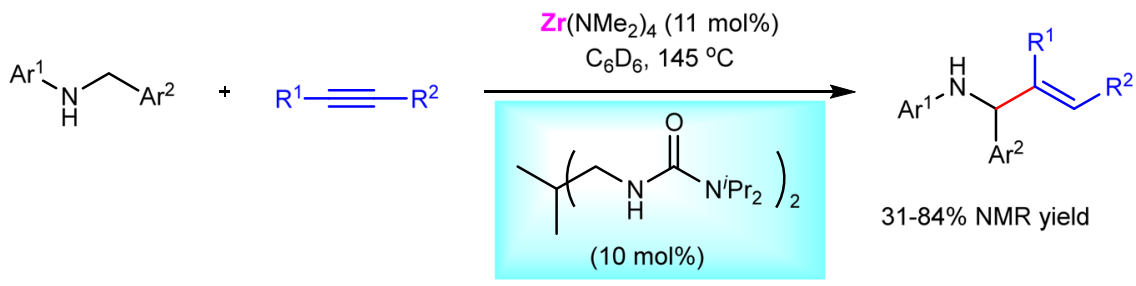

Strategy I: early transition metal Zr with bulky tetradentate ligand (Schafer)

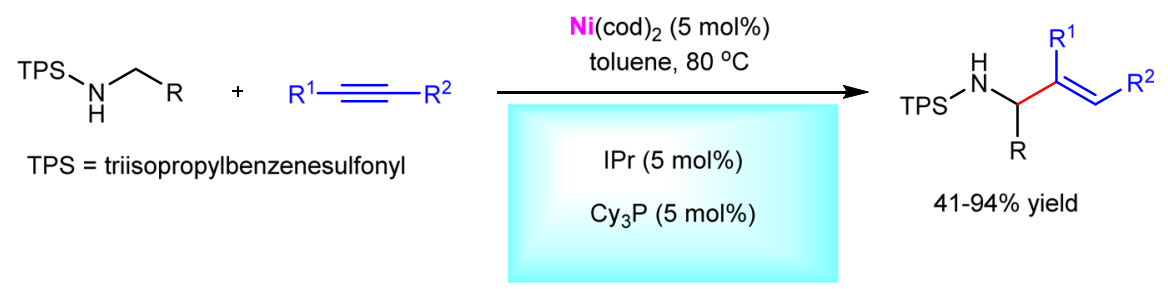

Strategy II: late transition metal Ni with dual ligands (this work)

Fig. 1 Transition metal-catalyzed hydroaminoalkylation of alkynes. a Pioneering investigation using stoichiometric Zr-complex (Buchwald). b Strategy I using early transition metal $\mathrm{Zr}$ and bulky tetradentate ligand (Schafer). c Strategy II using late transition metal Ni with dual ligands (this work). IPr = 1,3-bis (2,6-diisopropylphenyl)-2,3-dihydro-1H-imidazole. $\mathrm{Cy}_{3} \mathrm{P}=$ tricyclohexylphosphine. 


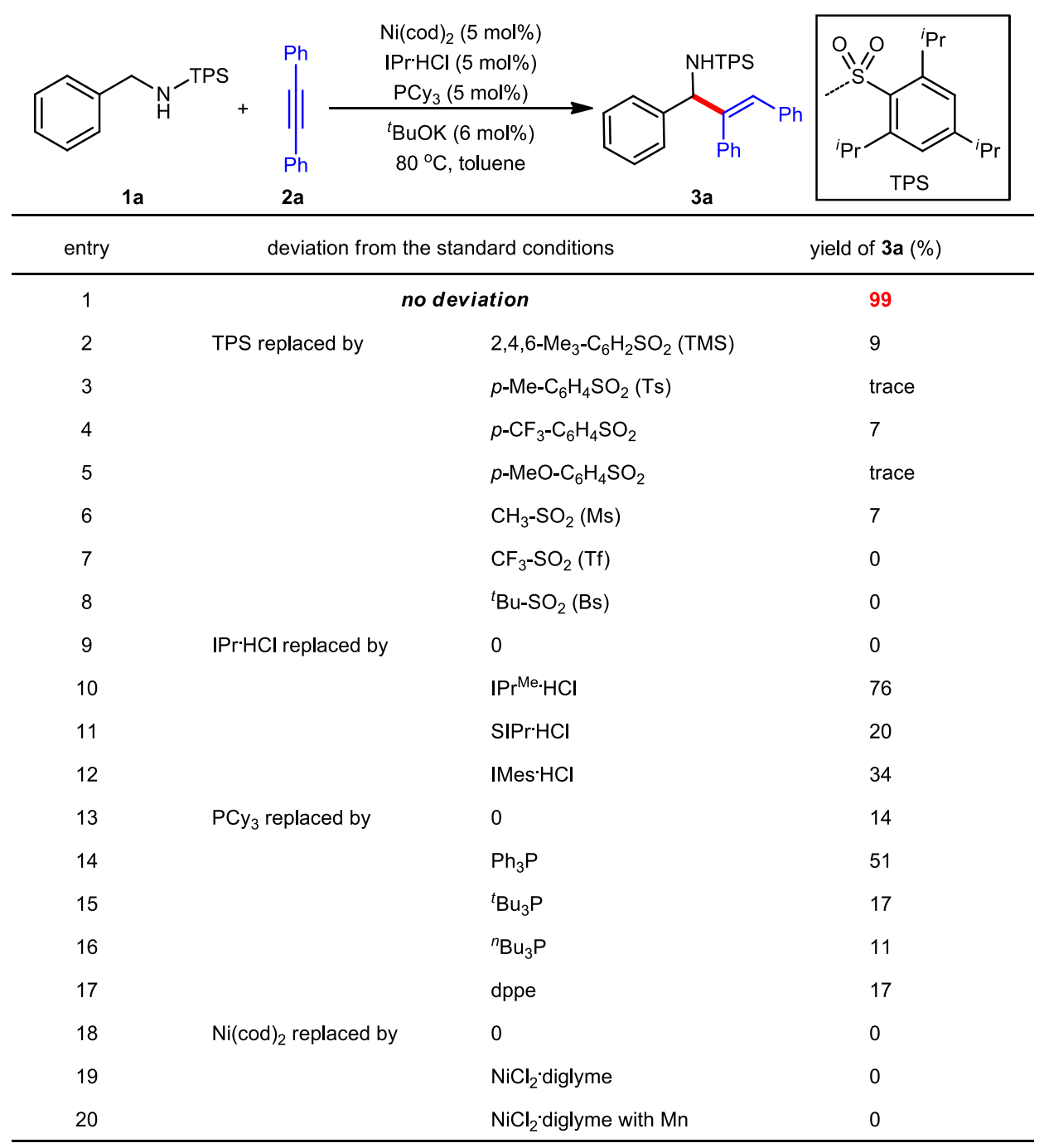

Fig. 2 Reaction optimization. Reaction conditions: 1a $(0.20 \mathrm{mmol}), \mathbf{2 a}(0.22 \mathrm{mmol})$, toluene $(2.0 \mathrm{~mL})$ under $\mathrm{N}_{2}$ for $1 \mathrm{~h}$; yield was determined by ${ }^{1} \mathrm{H} \mathrm{NMR}$ using $\mathrm{Cl}_{2} \mathrm{CHCHCl}_{2}$ as the internal standard. $I \mathrm{Pr}^{\mathrm{Me}}=1,3-$-bis(2,6-diisopropylphenyl)-4,5-dimethyl-2,3-dihydro- $1 \mathrm{H}$-imidazole. $\mathrm{SIPr}=1,3-b i s(2,6-$ diisopropylphenyl)imidazolidine. IMes =1,3-dimesityl-2,3-dihydro-1H-imidazole. dppe =1,2-bis(diphenylphosphino)ethane.

(TPS) was identified as the superior $\mathrm{N}$-protecting group and $\mathrm{Ni} /$ $\mathrm{IPr} / \mathrm{PCy}_{3}$ was identified as the optimal catalyst. With their combination, hydroaminoalkylation of alkyne $\mathbf{2 a}$ with N-TPS amine la smoothly proceeded under mild conditions $\left(80^{\circ} \mathrm{C}\right)$, providing the corresponding allylic amine $\mathbf{3 a}$ in nearly quantitative yield (Fig. 2, entry 1).

Control experiments showed that the alteration of TPS resulted into significantly diminished yields (entries 2-8). For example, the replacement of isopropyl groups (TPS) by methyl groups (TMS) gave only $9 \%$ yield (entry 2 ). Common $p$-tolylsulfonyl (Ts) further decreased the yield to a trace amount (entry 3 ). The combination of $\mathrm{NHC}(\mathrm{IPr})$ and phosphine $\left(\mathrm{PCy}_{3}\right)$ ligands also proved critical to the reaction (entries 9-17). The absence of IPr. $\mathrm{HCl}$ completely inhibited the reaction (entry 9), whereas the reaction still gave $3 \mathrm{a}$ in $14 \%$ yield without the addition of $\mathrm{PCy}_{3}$ (entry 13), demonstrating the vital role of IPr and the promoting effect of $\mathrm{PCy}_{3}$. In fact, a yield of $68 \%$ was detected with IPr alone at an elevated temperature $\left(110^{\circ} \mathrm{C}\right)$ but with poor reproducibility (see the Supplementary Information for details). Other carbenes and phosphines were less effective (entries $10-12$ and 14-17). Without $\mathrm{Ni}(\operatorname{cod})_{2}$ or with other nickel species, the reaction did not work (entries 18-20).
Scope of amines and alkynes. Under the optimized conditions, various N-TPS amines were then examined (Fig. 3). Results showed that the reaction tolerated a broad range of functional groups on the phenyl ring of $\mathrm{N}$-benzylamines, including simple alkyl (Me, $\mathbf{3 b}-\mathbf{3 d}$ ), electron-donating groups (alkoxy, $\mathbf{3 e}$ and $\mathbf{3 f}$ ), and electron-withdrawing groups $\left(\mathrm{OCF}_{3}, \mathrm{~F}, \mathrm{Cl}, \mathrm{CF}_{3}, \mathrm{CN}\right.$, and $\mathrm{CO}_{2} \mathrm{Me}, \mathbf{3 g}-\mathbf{3 n}$ ), providing the corresponding allylic amines in $62-94 \%$ yields. In addition, the position of substituents did not have a strong influence on the reaction yield $(\mathbf{3 b}-\mathbf{3 d}$ and $\mathbf{3 h}-\mathbf{3 j})$. Notably, both 1-naphthyl (3o) and heteroaryl (3p) instead of the phenyl of 1a also worked well, affording both $86 \%$ yields. When the phenyl was replaced by the alkenyl, a decreased yield was obtained $(45 \%, 3 q)$ in the presence of $10 \mathrm{~mol} \%$ of the catalyst at $110{ }^{\circ} \mathrm{C}$. Notably, various $\mathrm{N}$-alkylamines were still compatible with the reaction $(3 \mathbf{r}-\mathbf{3 u}, 41-54 \%$ yields), but requiring harsher conditions $\left(130{ }^{\circ} \mathrm{C}\right.$ and $20 \mathrm{~mol} \%$ catalyst) and a Ts protecting group. We reasoned that higher $\mathrm{a}-\mathrm{C}-\mathrm{H}$ bond strength of alkylamines than that of benzylamines and higher activation energy may result in this situation.

Next, a broad range of alkynes were investigated under the standard conditions (Fig. 4). Various diaryl alkynes bearing alkyls $(\mathbf{4 a}-\mathbf{4 e})$ and electron-donating groups (4f) on the phenyl rings 


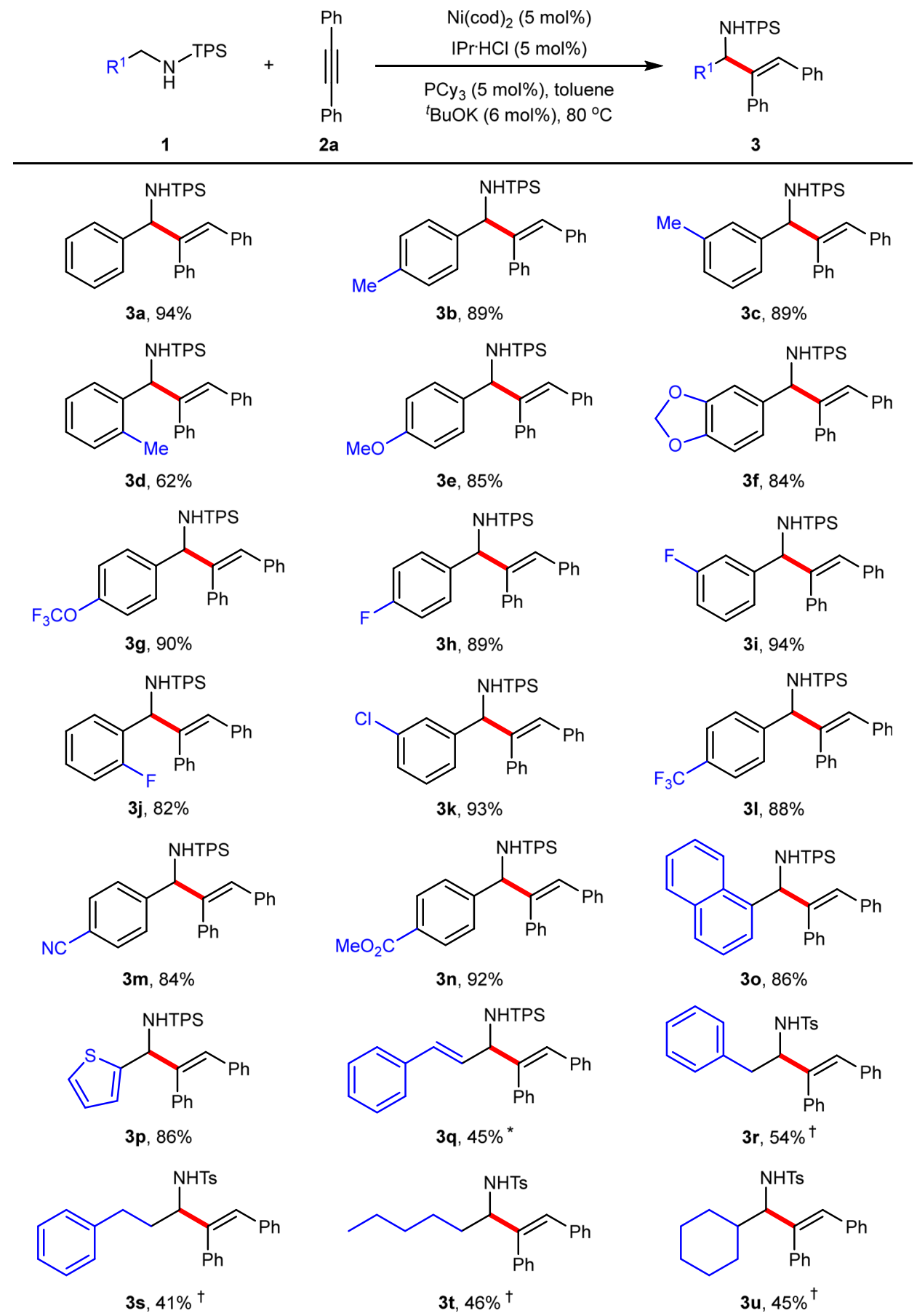

Fig. 3 Scope of amines. Reaction conditions: $1(0.20 \mathrm{mmol}), \mathbf{2 a}(0.22 \mathrm{mmol})$, toluene $(2.0 \mathrm{~mL})$ under $\mathrm{N}_{2}$ for $1-12 \mathrm{~h}$; yield of isolated products. ${ }^{*} \mathrm{Ni}(\mathrm{cod}){ }_{2}$ (10 mol\%), IPr. HCl (10 mol\%), $\mathrm{PCy} 3(10 \mathrm{~mol} \%),{ }^{t} \mathrm{BuOK}(12 \mathrm{~mol} \%)$ at $\left.110{ }^{\circ} \mathrm{C} .{ }^{\dagger} \mathrm{Ni}(\mathrm{cod})\right)_{2}(20 \mathrm{~mol} \%), \mathrm{IMes} \cdot \mathrm{HCl}(20 \mathrm{~mol} \%), \mathrm{PCy} 3(20 \mathrm{~mol} \%),{ }^{t} \mathrm{BuOK}(22 \mathrm{~mol}$ $\%)$ at $130{ }^{\circ} \mathrm{C}$. Ts $=$ tolylsulfonyl.

were well compatible with the current reaction, providing the corresponding products in $79-92 \%$ yields. Notably, 2-tolylalkyne gave a 1:1 mixture of $E: Z$ isomers $(4 \mathrm{c})$, probably because the significant steric hindrance on the aryl ring forced the alkene to isomerize.

In contrast, electron-deficient groups such as $\mathrm{OCF}_{3}(\mathbf{4 g}), \mathrm{F}$ (4h), and $\mathrm{CF}_{3}(4 \mathbf{i})$ on the phenyl ring led to slightly lower yields even at a higher temperature. In addition, both dialkyl alkynes (4j and $\mathbf{4 k}$ ) and alkyl aryl alkynes $(\mathbf{4 l}-\mathbf{4 p})$ were well tolerated, providing both good yields and good to excellent regioselectivities. For example, 1-phenylpropyne gave 8.1:1 regioisomeric ratio (4l), and the change of methyl to ethyl significantly increased the ratio to 20:1 (4m). Bulkier alkyls (4n-4p) or silyl (4q) led to a single regioisomer. However, non-symmetrical dialkyl alkyne (4r) cannot afford good regioselectivity probably owing to low differentiation between isopropyl and methyl groups.

Reaction utility and mechanistic investigation. To demonstrate the utility of the reaction, a gram-scale reaction of the model substrates was conducted under the standard conditions, affording the desired product $3 \mathbf{a}$ in $88 \%$ yield, without significant loss of the yield (Fig. 5a). In addition, the formed allylic amine $\mathbf{3 a}$ can act as a versatile synthetic intermediate to participate into various 


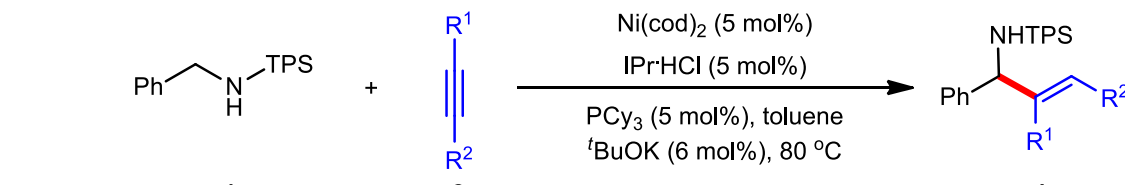

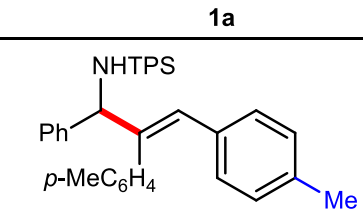

4a, $86 \%$<smiles>CCOC(=O)c1ccc(S(=O)(=O)NC(c2ccccc2)c2ccccc2)cc1</smiles>

4d, $92 \%$<smiles>C/C(=C\C(N[PH](=O)(F)=S)c1ccc(OC(F)(F)F)cc1)c1ccccc1</smiles>

4g, $60 \%$ *<smiles>CCC=C(CCCC)C(NS(=S)(=S)c1ccccc1)c1ccccc1</smiles>

4j, $91 \%$ *<smiles>CC/C(=C\c1ccccc1)C(NC(F)(F)F)c1ccccc1</smiles>

$4 \mathrm{~m}, 67 \%, 20: 1^{\dagger}$<smiles>COCCC(=Cc1ccccc1)C(NC(C)C)c1ccccc1</smiles>

$4 p, 50 \%^{\dagger}$<smiles>CCCC(=Cc1cccc(C)c1)C(NC(C)(C)C)c1ccccc1</smiles>

$4 b, 84 \%$<smiles>CCCCCC(=Cc1ccc(C(C)(C)C)cc1)C(NC(C)(C)C)c1ccccc1</smiles>

$4 e, 88 \%$<smiles>CCCCC(=Cc1ccc(F)cc1)C(NC(=O)O)c1ccccc1</smiles>

4h, $87 \%$ *<smiles>CC(C)(C)C=C(CBr)C(NP)c1ccccc1</smiles>

$4 k, 84 \%{ }^{*}$<smiles>CC(=Cc1ccccc1)C(NC(=S)NC(=O)c1ccccc1)c1ccccc1</smiles>

4n, $70 \%{ }^{\dagger}$<smiles>CC(F)(F)NC(C(=Cc1ccccc1)S(C)(=O)=O)c1ccccc1</smiles>

4q, $55 \%^{\dagger}$<smiles>CNC(=S)NC(C(C)=Cc1ccccc1OC)C(c1ccccc1)c1ccccc1</smiles>

4c, $79 \%, 1: 1(E: Z)^{*}$<smiles>COC(=O)/C(=C\c1ccc(OC)cc1)C(NC(C)(F)F)c1ccccc1</smiles>

4f, $92 \%$<smiles>FC(F)(F)CCCC(=Cc1ccc(C(F)(F)F)cc1)C(NC(F)(F)F)c1ccccc1</smiles>

$4 i, 65 \%$ *<smiles>CC(=Cc1ccccc1)C(NP)c1ccccc1</smiles>

4I, $67 \%, 8.1: 1^{\dagger}$<smiles></smiles>

4o, $88 \%^{\dagger}$<smiles>CC=C(CCC)C(NC(=S)NC)c1ccccc1</smiles>

$4 \mathbf{r}, 69 \%, 2.2: 1^{\dagger}$

Fig. 4 Scope of alkynes. Reaction conditions: $1 \mathbf{a}(0.20 \mathrm{mmol}), \mathbf{2}(0.22 \mathrm{mmol})$, toluene $(2.0 \mathrm{~mL})$ under $\mathrm{N}_{2}$ for $1-12 \mathrm{~h}$; yield of isolated products. ${ }^{*} 110{ }^{\circ} \mathrm{C}$. ${ }^{\dagger} \mathrm{Ni}$ $(\mathrm{cod})_{2}(10 \mathrm{~mol} \%), \mathrm{IPr} \cdot \mathrm{HCl}(10 \mathrm{~mol} \%), \mathrm{PCy}_{3}(10 \mathrm{~mol} \%),{ }^{\mathrm{t}} \mathrm{BuOK}(12 \mathrm{~mol} \%)$ at $110^{\circ} \mathrm{C}$ and regioisomer ratio. $\mathrm{TMS}=$ trimethylsilyl.

transformations. For example, hydrogenation followed by typical deprotection protocol of the sulfonyl group provided compound 5 in $68 \%$ yield. Moreover, direct oxidation of $\mathbf{3 a}$ resulted into a synthetically useful $\alpha$-amino ketone $\mathbf{6}$ in $90 \%$ yield.

To gain insights into the reaction mechanism, some mechanistic experiments were carried out. Deuterium labeling experiments revealed that $100 \%$ allylic deuterium and $94 \%$ olefinic deuterium existed in product $\boldsymbol{d}-\mathbf{3 a}$, together with deuterated $Z$ stilbene $(12 \%$ yield). This result showed that there was partial deuterium-scrambling at the vinylic position, which may be ascribed to a reversible insertion of $\mathrm{C}=\mathrm{C}$ double bonds in products or stilbene into $\mathrm{N}-\mathrm{H}$ bonds (Fig. 5b). In addition, deuterated $Z$-stilbene was obtained, indicating that a part of alkynes were reduced during the reaction process. Crossover experiments between $\boldsymbol{d}-\mathbf{1 a}$ and 1e suggested that the allylic and olefinic hydrogens may originate from different amide molecules (Fig. 5c), excluding an oxidative addition pathway. The observed kinetic isotopic effect $\left(k_{\mathrm{H}} / k_{\mathrm{D}}=2.7\right.$ in the intermolecular competitive reaction and $k_{\mathrm{H}} / k_{\mathrm{D}}=2.2$ in parallel reactions, Fig. $5 \mathrm{~d}$ ) implied that the cleavage of the benzylic $\mathrm{C}-\mathrm{H}$ bond could be involved in the rate-determining step. Notably, in case of dimethylamino benzylic amide $\mathbf{1 v}$ as the substrate, imine $\mathbf{1 v}^{\prime}$ was detected (Fig. 5e). Moreover, the competitive reaction between amide and the imine showed that both of them gave the corresponding products in comparable yields (see Supplementary Information).

These results suggested that an imine intermediate could be involved in the catalytic cycle. In addition, the stoichiometric reaction of a five-membered nickelacycle ${ }^{42-44}$ and amide 1a with or without IPr afforded the desired product $\mathbf{3 b}$ in $68 \%$ and $9 \%$ yields, respectively, suggesting that both the nickelacycle and IPr were critical to the reaction (Fig. 5f). Based on these mechanistic experiments and previous literature reports ${ }^{45-49}$, a possible reaction mechanism was proposed (Fig. 6). At the induction stage, the nickel-catalyzed transfer hydrogenation of alkyne $\mathbf{2 a}$ with amine $\mathbf{1 a}$ furnishes $Z$-stilbene and imine $\mathbf{1} \mathbf{a}^{\prime}$. Then, $\mathbf{1} \mathbf{a}^{\prime}, \mathbf{2 a}$ 
a

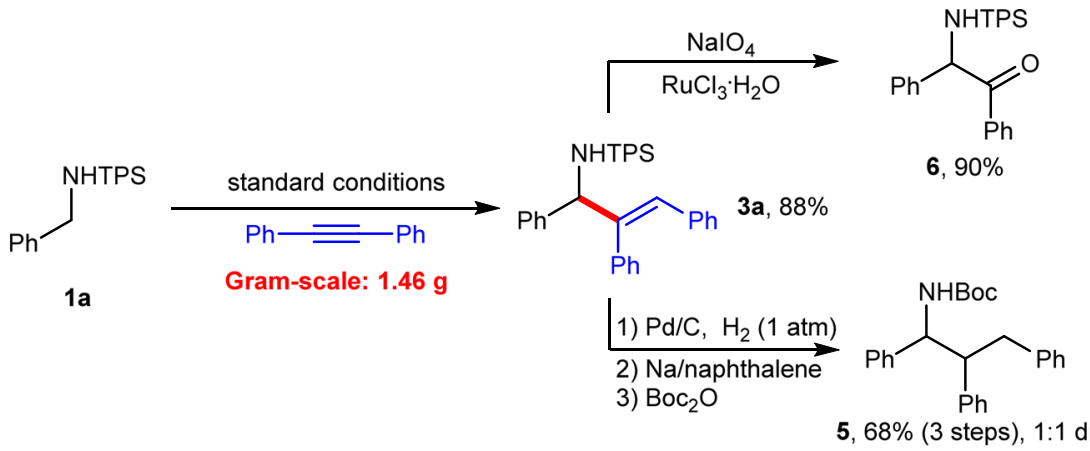

b

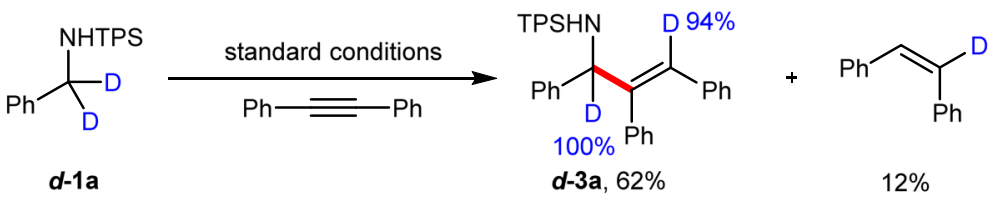

c

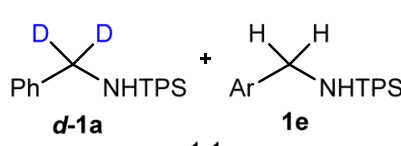

$1: 1$

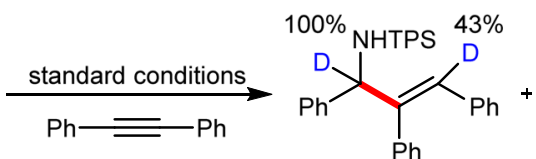

d-3a, $33 \%$

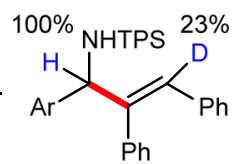

d-3e, $50 \%$

d<smiles>S=PNC(c1ccccc1)c1ccccc1</smiles>

1:1<smiles>[2H]C([2H])(NC(=O)[O-])c1ccccc1</smiles><smiles>C[13CH][13CH]c1ccccc1</smiles>

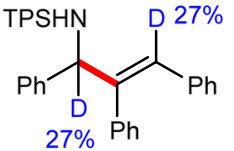

$88 \%, k_{\mathrm{H}} / k_{\mathrm{D}}=2.7$

parallel experiments: $k_{H} / k_{D}=2.2$

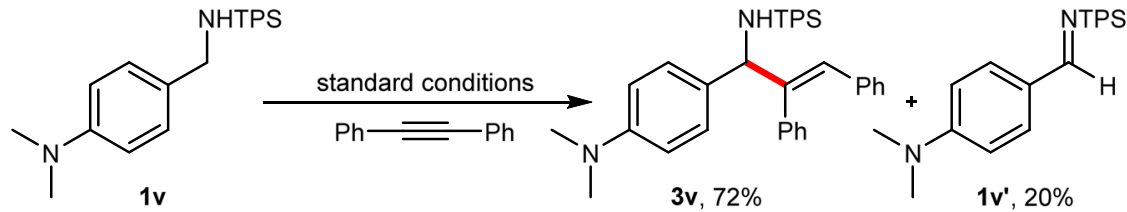

$\mathbf{f}$

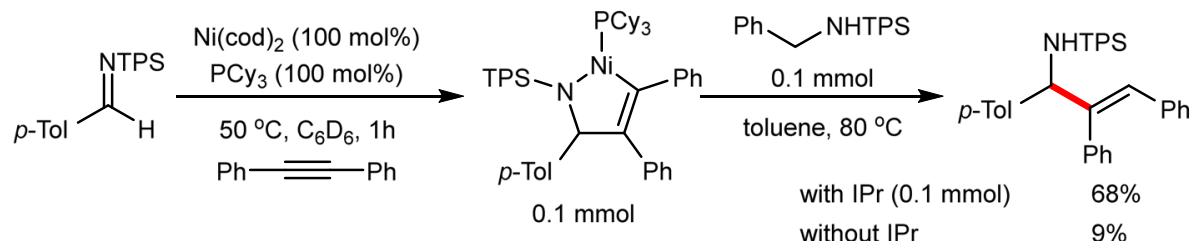

Fig. 5 Synthetic utility and mechanistic experiments. a Gram-scale reaction and product transformation. b Deuterium labeling experiments. c Intermolecular competition. d Determination of kinetic isotope effect. e Detection of imine. $\mathbf{f}$ Stoichiometric reaction.

and the nickel catalyst undergo an oxidative cyclometallation to generate nickelacycle $\mathbf{B}$, which is subsequently protonated by $\mathbf{1 a}$. The resulting intermediate $\mathbf{C}$ then proceeds through a direct intramolecular hydrogen transfer to give $\mathrm{Ni}$ - product complex $\mathbf{D}$. Finally, catalyst transfer between $\mathbf{D}$ and $\mathbf{2 a}$ occurs, releasing product $3 \mathbf{a}$ and completing the catalytic cycle.

To further shed light on each individual elementary step of the catalytic reaction, we performed density-functional theory (DFT) calculations on the model reaction of $N$-benzylbenzenesulfonamide and $\mathbf{2} \mathbf{a}$ in the presence of a simplified Ni/NHC catalyst. At the induction stage (Fig. 7a), Ni-amine-alkyne complex IN1 first undergoes a ligand-to-ligand hydrogen transfer (LLHT) via TS1 with an activation Gibbs energy of $14.3 \mathrm{kcal} / \mathrm{mol}$. The resulting intermediate IN2 proceeds through a conformational change into its reactive form IN3. Then, another intramolecular hydrogen transfer occurs via TS2 with an overall activation Gibbs energy of $18.1 \mathrm{kcal} / \mathrm{mol}$, generating $\mathrm{Ni}$-imine-alkene complex IN4. Finally, ligand exchange between IN4 and 2a takes place, leading to Ni-imine-alkyne complex IN5 and Z-stilbene. At the productformation stage (Fig. 7b), IN5 first undergoes an oxidative cyclometallation via TS3 with an activation Gibbs energy of 23.7 $\mathrm{kcal} / \mathrm{mol}$, generating nickelacycle IN6. Then, another amine substrate enters the catalytic cycle, forming hydrogen-bonded complex IN7. Subsequently, an intramolecular proton transfer occurs via TS4, leading to intermediate IN8, which then proceeds through a series of ligand exchange processes. After that, the resulting reactive isomer IN9 transforms into $\mathrm{Ni}$-product complex IN10 via the turnoverlimiting intramolecular hydrogen transfer via TS5 with an overall 


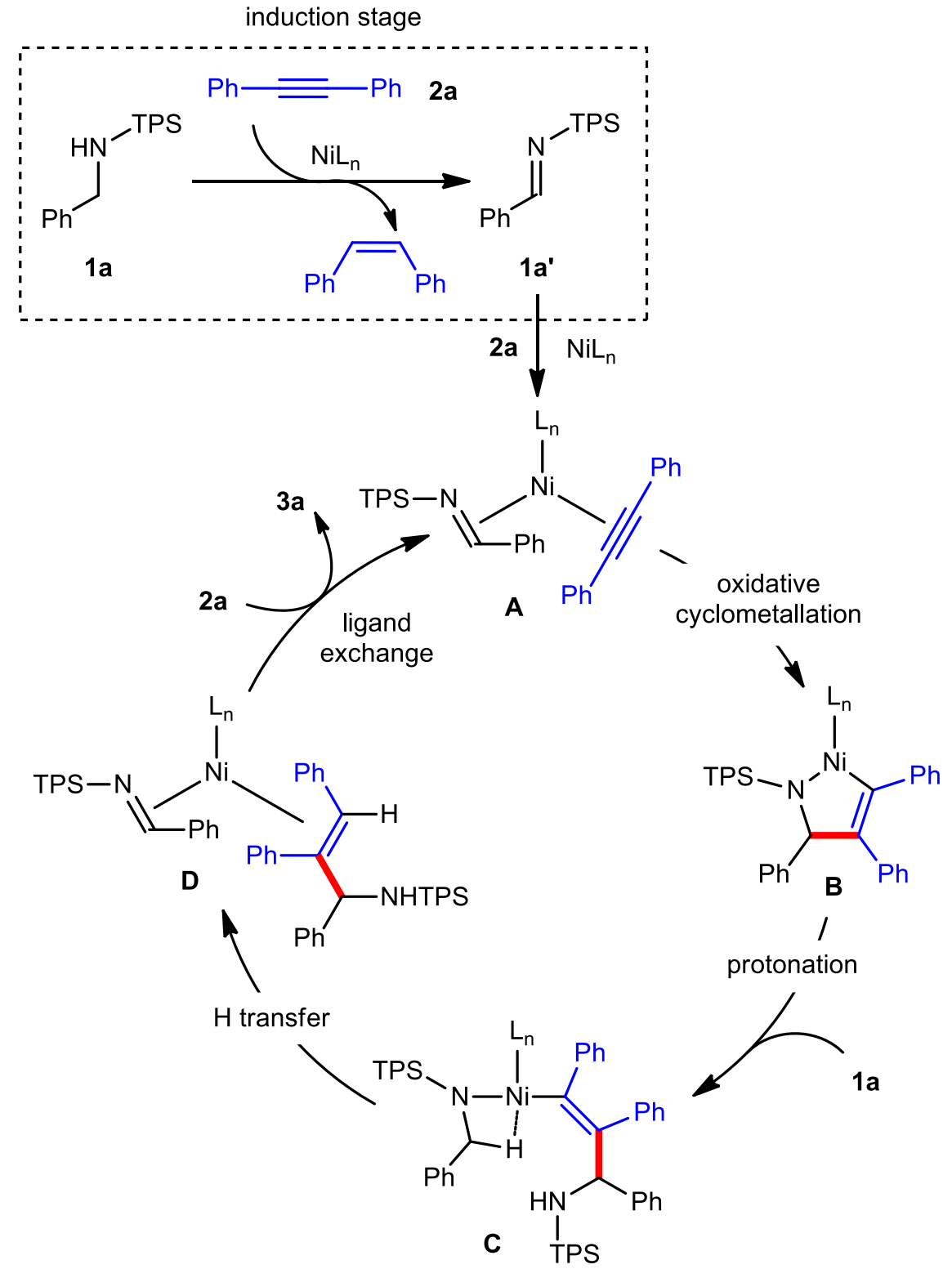

Fig. 6 Proposed mechanism. Induction stage and catalytic cycle.

activation Gibbs energy of $24.8 \mathrm{kcal} / \mathrm{mol}$, which is in accordance with the observed kinetic isotopic effect (Fig. 5d). Finally, ligand exchange between IN10 and 2a takes place, releasing the final product and IN5, which triggers the next catalytic cycle. DFT calculations with TPS-protected substrate 1a and IPr ligand indicated that the overall activation Gibbs energy is $22.4 \mathrm{kcal} / \mathrm{mol}$. Replacement of TPS by Ts leads to a higher overall activation Gibbs energy of $24.9 \mathrm{kcal} / \mathrm{mol}$. These results suggested that, as compared with the Ts group, a ca. 30 fold acceleration effect of the TPS group would be expected at $80^{\circ} \mathrm{C}$, which nicely reproduced the experimentally observed superior performance of the TPS protecting group (Fig. 2, entry 1 vs. entry 3 ). In addition, DFT calculations also suggested that the presence of $\mathrm{PCy}_{3}$ may not reduce the overall activation Gibbs energy of the Nicatalyzed reaction since replacement of $\mathrm{NHC}$ by $\mathrm{PCy}_{3}$ did not promote the turnover-limiting hydrogen transfer step (see Supplementary Fig. 8). Instead, $\mathrm{PCy}_{3}$ may act as an auxiliary ligand to facilitate the generation of the catalytic species and/or to inhibit catalyst deactivation.

\section{Methods}

General procedure for hydroaminoalkylation. To a $15 \mathrm{~mL}$ pressure tube were added $\mathrm{Ni}(\mathrm{cod})_{2}(2.75 \mathrm{mg}, 0.01 \mathrm{mmol}), \mathrm{IPr} \cdot \mathrm{HCl}(4.25 \mathrm{mg}, 0.01 \mathrm{mmol}), \mathrm{PCy}_{3}(2.8 \mathrm{mg}$, $0.01 \mathrm{mmol}), \mathrm{KO}^{t} \mathrm{Bu}(1.34 \mathrm{mg}, 0.012 \mathrm{mmol})$, toluene $(2.0 \mathrm{~mL})$, alkynes $(0.22 \mathrm{mmol})$ and amines $(0.20 \mathrm{mmol})$ in a glove box. The tube was sealed with a Teflon cap and the mixture was stirred at 80 or $110^{\circ} \mathrm{C}$ for $1-12 \mathrm{~h}$. After cooled to room temperature, the crude product was filtered through a short pad of Celite, and the filtrate was concentrated under vacuum. The resulting residue was obtained by chromatography on silica gel column with petroleum ether/ethyl acetate as the eluent.

\section{Data availability}

The authors declare that the data supporting the findings of this study are available within the article and its Supplementary Information file. For the experimental procedures and data of NMR, see Supplementary Methods in Supplementary Information file. For computed energies and Cartesian coordinates of the stationary points see Supplementary Data 1.

Received: 12 January 2021; Accepted: 18 March 2021; Published online: 21 June 2021 


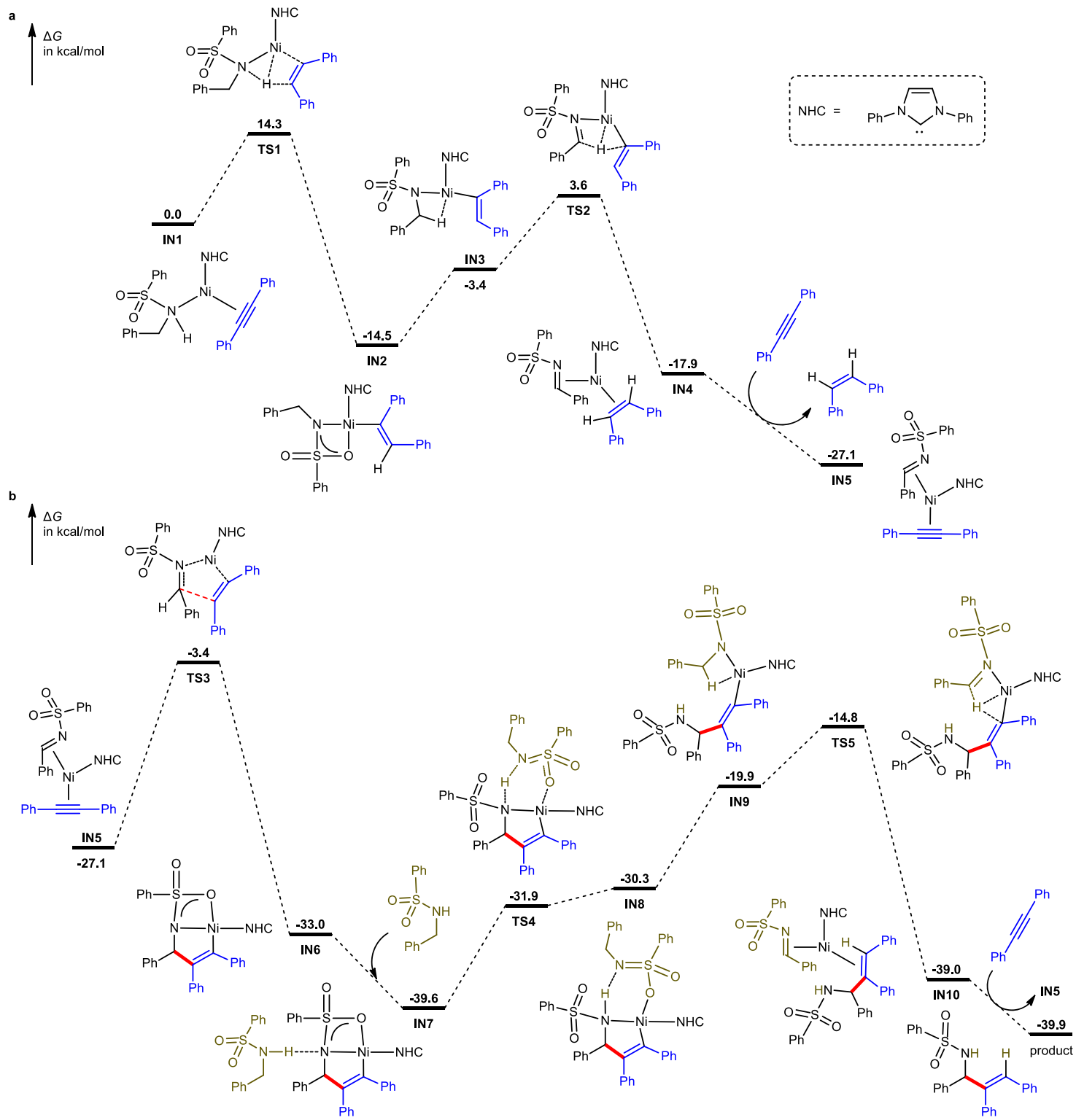

Fig. 7 DFT calculations. a Induction stage for imine formation. b Product-formation stage.

\section{References}

1. Johannsen, M. \& Jørgensen, K. A. Allylic amination. Chem. Rev. 98, 1689-1708 (1998).

2. Skoda, E. M., Davis, G. C. \& Wipf, P. Allylic amines as key building blocks in the synthesis of (E)-alkene peptide isosteres. Org. Process Res. Dev. 16, 26-34 (2012).

3. Schnur, R. C. \& Corman, M. L. Tandem [3,3]-sigmatropic rearrangements in an ansamycin: stereospecific conversion of an (S)-allylic alcohol to an (S)allylic amine derivative. J. Org. Chem. 59, 2581-2584 (1994).

4. Petranyi, G., Ryder, N. S. \& Stgtz, A. Allylamine derivatives: new class of synthetic antifungal agents inhibiting fungal squalene epoxidase. Science 224, 1239 (1984).

5. Paul, A. \& Seidel, D. $\alpha$-Functionalization of cyclic secondary amines: Lewis acid promoted addition of organometallics to transient imines. J. Am. Chem. Soc. 141, 8778-8782 (2019).

6. Chen, W., Ma, L., Paul, A. \& Seidel, D. Direct $\alpha-\mathrm{C}-\mathrm{H}$ bond functionalization of unprotected cyclic amines. Nat. Chem. 10, 165-169 (2018).

7. Xiao, L.-J. et al. Nickel(0)-catalyzed hydroalkenylation of imines with styrene and its derivatives. Angew. Chem. Int. Ed. 57, 3396-3400 (2018).

8. Paul, S. \& Guin, J. Radical C $\left(\mathrm{sp}^{3}\right)-\mathrm{H}$ alkenylation, alkynylation and allylation of ethers and amides enabled by photocatalysis. Green. Chem. 19, 2530-2534 (2017).
9. Deng, H.-P., Fan, X.-Z., Chen, Z.-H., Xu, Q.-H. \& Wu, J. Photoinduced nickelcatalyzed chemo- and regioselective hydroalkylation of internal alkynes with ether and amide $\alpha$-hetero $\mathrm{C}\left(\mathrm{sp}^{3}\right)-\mathrm{H}$ bonds. J. Am. Chem. Soc. 139, 13579-13584 (2017).

10. Xiang, B. et al. Lewis acid catalyzed friedel-crafts alkylation of alkenes with trifluoropyruvates. J. Org. Chem. 81, 3929-3935 (2016).

11. Wei, G. et al. Enantioselective aerobic oxidative $\mathrm{C}\left(\mathrm{sp}^{3}\right)-\mathrm{H}$ olefination of amines via cooperative photoredox and asymmetric catalysis. ACS Catal. 6, 3708-3712 (2016).

12. Sølvhøj, A., Ahlburg, A. \& Madsen, R. Dimethylzinc-initiated radical coupling of $\beta$-bromostyrenes with ethers and amines. Chem. Eur. J. 21, 16272-16279 (2015).

13. Liu, R.-R. et al. Nickel-catalyzed enantioselective addition of styrenes to cyclic n-sulfonyl a-ketiminoesters. ACS Catal. 5, 6524-6528 (2015).

14. Amaoka, Y. et al. Photochemically induced radical alkenylation of $\mathrm{C}\left(\mathrm{sp}^{3}\right)-\mathrm{H}$ bonds. Chem. Sci. 5, 4339-4345 (2014).

15. Sun, M., Wu, H. \& Bao, W. $\alpha$-Vinylation of amides with arylacetylenes: synthesis of allylamines under metal-free conditions. Org. Biomol. Chem. 11, 7076-7079 (2013).

16. Wei, Y. \& Shi, M. Recent advances in organocatalytic asymmetric MoritaBaylis-Hillman/aza-Morita-Baylis-Hillman reactions. Chem. Rev. 113, 6659-6690 (2013) 
17. Li, L., Zhang, X.-S., Zhu, Q.-L. \& Shi, Z.-J. Olefinic C-H bond addition to aryl aldehyde and its $\mathrm{N}$-sulfonylimine via Rh catalysis. Org. Lett. 14, 4498-4501 (2012).

18. Xie, Y., Hu, J., Wang, Y., Xia, C. \& Huang, H. Palladium-catalyzed vinylation of aminals with simple alkenes: a new strategy to construct allylamines. J. Am. Chem. Soc. 134, 20613-20616 (2012)

19. Zhou, C.-Y., Zhu, S.-F., Wang, L.-X. \& Zhou, Q.-L. Enantioselective nickelcatalyzed reductive coupling of alkynes and imines. J. Am. Chem. Soc. 132, 10955-10957 (2010).

20. Ngai, M.-Y., Barchuk, A. \& Krische, M. J. Enantioselective iridium-catalyzed imine vinylation: Optically enriched allylic amines via alkyne-imine reductive coupling mediated by hydrogen. J. Am. Chem. Soc. 129, 12644-12645 (2007).

21. Kong, J.-R., Cho, C.-W. \& Krische, M. J. Hydrogen-mediated reductive coupling of conjugated alkynes with ethyl ( $N$-sulfinyl)iminoacetates: synthesis of unnatural $\alpha$-amino acids via rhodium-catalyzed $\mathrm{C}-\mathrm{C}$ bond forming hydrogenation. J. Am. Chem. Soc. 127, 11269-11276 (2005).

22. Patel, S. J. \& Jamison, T. F. Catalytic three-component coupling of alkynes, imines, and organoboron reagents. Angew. Chem. Int. Ed. 42, 1364-1367 (2003).

23. Sakaguchi, S., Kubo, T. \& Ishii, Y. A three-component coupling reaction of aldehydes, amines, and alkynes. Angew. Chem. Int. Ed. 40, 2534-2536 (2001)

24. Edwards, P. M. \& Schafer, L. L. Early transition metal-catalyzed C-H alkylation: hydroaminoalkylation for $\mathrm{Csp}^{3}-\mathrm{Csp}^{3}$ bond formation in the synthesis of selectively substituted amines. Chem. Commun. 54, 12543-12560 (2018).

25. Roesky, P. W. Catalytic hydroaminoalkylation. Angew. Chem. Int. Ed. 48, 4892-4894 (2009).

26. Chong, E., Garcia, P. \& Schafer, L. L. Hydroaminoalkylation: early-transitionmetal-catalyzed $\alpha$-alkylation of amines. Synthesis 46, 2884-2896 (2014).

27. Ryken, S. A. \& Schafer, L. L. N,O-chelating four-membered metallacyclic titanium(IV) complexes for atom-economic catalytic reactions. Acc. Chem. Res. 48, 2576-2586 (2015).

28. Hannedouche, J. \& Schulz, E. Hydroamination and hydroaminoalkylation of alkenes by group 3-5 elements: recent developments and comparison with late transition metals. Organometallics 37, 4313-4326 (2018).

29. Shi, L. \& Xia, W. Photoredox functionalization of $\mathrm{C}-\mathrm{H}$ bonds adjacent to a nitrogen atom. Chem. Soc. Rev. 41, 7687-7697 (2012).

30. Nakajima, K., Miyake, Y. \& Nishibayashi, Y. Synthetic utilization of aaminoalkyl radicals and related species in visible light photoredox catalysis. Acc. Chem. Res. 49, 1946-1956 (2016).

31. Dong, Z., Ren, Z., Thompson, S. J., Xu, Y. \& Dong, G. Transition-metalcatalyzed C-H alkylation using alkenes. Chem. Rev. 117, 9333-9403 (2017).

32. Buchwald, S. L., Watson, B. T., Wannamaker, M. W. \& Dewan, J. C. Zirconocene complexes of imines: general synthesis, structure, reactivity, and in situ generation to prepare geometrically pure allylic amines. J. Am. Chem. Soc. 111, 4486-4494 (1989).

33. Grossman, R. B., Davis, W. M. \& Buchwald, S. L. Enantioselective, zirconiummediated synthesis of allylic amines. J. Am. Chem. Soc. 113, 2321-2322 (1991).

34. Broene, R. D. \& Buchwald, S. L. Zirconocene complexes of unsaturated organic molecules: new vehicles for organic synthesis. Science 261, 1696-1701 (1993).

35. Harris, M. C. J., Whitby, R. J. \& Blagg, J. A practical procedure for the elaboration of amines via zirconocene $\eta^{2}$-imine complexes. Tetrahedron Lett. 35, 2431-2434 (1994).

36. Gao, Y., Yoshida, Y. \& Sato, F. In situ generation of titanium-imine complexes from imines and $\mathrm{Ti}\left(\mathrm{O}^{i} \mathrm{Pr}\right)_{4} / 2^{i} \mathrm{PrMgX}$, and their reactions with alkynes, nitriles and imines. Synlett 1353-1354 (1997).

37. Barluenga, J., Rodriguez, F., Alvarez-Rodrigo, L., Zapico, J. M. \& Fananas, F. J. Zirconium-mediated coupling reactions of amines and enol or allyl ethers: Synthesis of allyl- and homoallylamines. Chem. Eur. J. 10, 109-116 (2004)

38. Cummings, S. A., Tunge, J. A. \& Norton, J. R. Synthesis and reactivity of zirconaaziridines. Top. Organomet. Chem. 10, 1-39 (2004).

39. Kristian, K. E. et al. Mechanism of the reaction of alkynes with a "constrained geometry" zirconaaziridine. $\mathrm{PMe}_{3}$ dissociates more rapidly from the constrained geometry complex than from its $\mathrm{Cp} 2$ analogue. Organometallics 28, 493-498 (2009).

40. Bahena, E. N., Griffin, S. E. \& Schafer, L. L. Zirconium-catalyzed hydroaminoalkylation of alkynes for the synthesis of allylic amines. J. Am. Chem. Soc. 142, 20566-20571 (2020).

41. Kaper, T. et al. Intermolecular hydroaminoalkylation of alkynes. Chem. Eur. J. 27, 6899-6903 (2021).

42. Ogoshi, S., Ikeda, H. \& Kurosawa, H. Formation of an aza-nickelacycle by reaction of an imine and an alkyne with nickel( 0$)$ : oxidative cyclization, insertion, and reductive elimination. Angew. Chem. Int. Ed. 46, 4930-4932 (2007).
43. Ogoshi, S., Ikeda, H. \& Kurosawa, H. Nickel-catalyzed [2+2+2] cycloaddition of two alkynes and an imine. Pure Appl. Chem. 80, 1115-1125 (2008).

44. Hoshimoto, Y., Ohata, T., Ohashi, M. \& Ogoshi, S. Nickel-catalyzed synthesis of $\mathrm{N}$-aryl-1,2-dihydropyridines by $[2+2+2]$ cycloaddition of imines with alkynes through T-shaped 14-electron aza-nickelacycle key intermediates. Chem. Eur. J. 20, 4105-4110 (2014).

45. Yao, W.-W., Li, R., Li, J.-F., Sun, J. \& Ye, M. NHC ligand-enabled Ni-catalyzed reductive coupling of alkynes and imines using isopropanol as a reductant. Green. Chem. 21, 2240-2244 (2019).

46. Cai, Y., Zhang, J.-W., Li, F., Liu, J.-M. \& Shi, S.-L. Nickel/N-heterocyclic carbene complex-catalyzed enantioselective redox-neutral coupling of benzyl alcohols and alkynes to allylic alcohols. ACS Catal. 9, 1-6 (2019).

47. Guihaumé, J., Halbert, S., Eisenstein, O. \& Perutz, R. N. Hydrofluoroarylation of alkynes with $\mathrm{Ni}$ catalysts. $\mathrm{C}-\mathrm{H}$ activation via ligand-to-ligand hydrogen transfer, an alternative to oxidative addition. Organometallics 31, 1300-1314 (2012).

48. Nakai, K., Yoshida, Y., Kurahashi, T. \& Matsubara, S. Nickel-catalyzed redoxeconomical coupling of alcohols and alkynes to form allylic alcohols. J. Am. Chem. Soc. 136, 7797-7800 (2014).

49. McCarren, P. R., Liu, P., Cheong, P. H.-Y., Jamison, T. F. \& Houk, K. N. Mechanism and transition-state structures for nickel-catalyzed reductive alkyne-aldehyde coupling reactions. J. Am. Chem. Soc. 131, 6654-6655 (2009).

\section{Acknowledgements}

This work was supported by the National Natural Science Foundation of China (21871145, 21933003, and 91856104), the Fundamental Research Funds for the Central Universities (63191601), High-Performance Computing Platform of Peking University, and National Supercomputing Center in Shenzhen (Shenzhen Cloud Computing Center).

\section{Author contributions}

W.-W.Y. discovered and developed the reactions. R.L., H.C., M.-K.C. performed part of synthetic experiments. Y.-X.L., Y.W., Z.-X.Y. performed the DFT calculations and analyzed the computational results, Y.-X.L., M.Y. conceived, designed the investigations and wrote the manuscript. W.-W.Y. wrote the Supplementary Information.

\section{Competing interests}

The authors declare no competing interests.

\section{Additional information}

Supplementary information The online version contains supplementary material available at https://doi.org/10.1038/s41467-021-24032-9.

Correspondence and requests for materials should be addressed to Y.-X.L., Z.-X.Y. or M.Y.

Peer review information Nature Communications thanks Stephen G. Newman and ShiLiang Shi for their contribution to the peer review of this work. Peer reviewer reports are available.

Reprints and permission information is available at http://www.nature.com/reprints

Publisher's note Springer Nature remains neutral with regard to jurisdictional claims in published maps and institutional affiliations.

Open Access This article is licensed under a Creative Commons Attribution 4.0 International License, which permits use, sharing, adaptation, distribution and reproduction in any medium or format, as long as you give appropriate credit to the original author(s) and the source, provide a link to the Creative Commons license, and indicate if changes were made. The images or other third party material in this article are included in the article's Creative Commons license, unless indicated otherwise in a credit line to the material. If material is not included in the article's Creative Commons license and your intended use is not permitted by statutory regulation or exceeds the permitted use, you will need to obtain permission directly from the copyright holder. To view a copy of this license, visit http://creativecommons.org/ licenses/by/4.0/

(C) The Author(s) 2021 